\title{
Psychotherapy from the Margins: How the Pressure to Adopt Evidence-Based-Treatments Conflicts with Social Justice-Oriented Practice
}

\author{
Lauren Rogers-Sirin, PhD \\ The College of Staten Island: City University of New York
}

\begin{abstract}
This article posits that the current interest in Empirically-Validated-Treatment (EVT) leads to a culture within psychology and counseling that presents cognitive-behavioral orientation (CBT) as the only legitimate approach to psychotherapy. This can be problematic not only because it narrows the scope of what is considered legitimate evidence of effectiveness, but also because CBT, like most Western approaches to psychotherapy, locates the origin of, and solution to, mental illness within the individual. On the other hand, social justice-oriented practice addresses how inequality, discrimination, oppression, and other societal-level forces contribute to mental illness at the individual level. Using a case example as an anchor for the ideas presented, I discuss how narrow definitions of empirical evidence have been used to justify the marginalization of multiple theoretical orientations, which in turn has led to therapies that can reinforce the marginalization of disadvantaged clients. I argue that this trend within the fields of clinical and counseling psychology reflects a wider trend in the United States and other Western cultures of xenophobia and fear of globalization. Those privileged by hierarchies of power are motivated to find uniformity and the appearance of a superior, more "correct" way of being, and to then attempt to control the lives of people who do not fit this way of being. Complexity and diversity, on the other hand, are experienced as threatening and alienating. Within psychotherapy too, CBT provides an appearance of universality in treatment that can be very appealing, yet social justice advocates have been very skeptical of claims of universality. I conclude with a discussion of how the narrowing of theoretical approaches may harm the fields of clinical and counseling psychology, and psychotherapy clients. I discuss what psychologists and counselors can do to counter this trend by taking action in professional organizations, academia, and in the therapy room.
\end{abstract}

Keywords: EVTs, CBT, feminist therapy, multicultural theory, social justice 


\section{Introduction}

Over the past several decades, clinicians have felt increasing pressure to adopt "EmpiricallyValidated-Treatments" (EVT) based on the idea that using scientifically supported treatments will help make sure patients and clients receive optimal care. The American Psychological Association has a list of EVTs, which are presented as the optimal treatment for various disorders, and the bulk of these are cognitive behavior interventions (CBT) (Samuels, 2008). This has led to a trend in which CBT is often presented as more "scientific" than other orientations $(\mathrm{H}$. Brown, 2013) and patients are encouraged to seek practitioners who practice EVTs (NIMH, 2016). This would make more sense if there were less controversy about how EVTs are determined. One result of this trend is an increasing sense of marginalization among other orientations within training programs and professional associations (Heatherington et al., 2013; Levy \& Anderson, 2013; Woolfolk \& Richardson, 2008). Heatherington et al. (2013), for example, found that among clinical psychology programs designated as "clinical science" programs, $80 \%$ of the faculty ascribed to CBT, and in other clinical programs $67 \%$ did. The increasing dominance of CBT is also felt outside academia with more and more practicing psychotherapists describing themselves as CBT practitioners (Norcross \& Karpiak, 2012).

Norcross and Karpiak (2012) reported that 31\% of clinical psychologists describe themselves as CBT, the largest group, with eclectic being the next largest at $22 \%$, psychodynamic only $18 \%$, and feminist not even represented. Several researchers have reported that practitioners of other theoretical orientations are feeling pressured to adopt CBT and increased tension between themselves and CBT practitioners (Jurist, 2013; Larsson, Broberg, \& Kaldo, 2013; Samuels, 2008). The increasing numbers of CBT therapists in and of itself is not a problem but the attitude that other theoretical orientations are non-scientific and represent sub-par treatment is both inaccurate and harmful to the public. For this reason, I believe that practitioners and educators have a responsibility to fight back against this trend. The fight is not against CBT, which is an enormously helpful therapy approach for many people, but rather is against the narrowing of the scope of what psychotherapy can be. I posit that this narrowing is more likely to alienate clients who already experience marginalization in modern American life. I discuss action steps at the conclusion of the paper.

The fundamental values of social justice-oriented practice seemingly pull in the opposite direction of the EVT movement (Minieri, Reese, Miserocchi, \& Pascale Hague, 2015). Rather than homogenizing treatments for various disorders, social justice-oriented practice calls for an ever widening and fluid understanding of health and wellness, and demands creativity in treatment. Feminist and multicultural theory have been central in psychology's (particularly counseling psychology's) movement for social justice. However, because of the narrow definitions of empiricism and evidence currently dominating the field of psychology, these theories have not been viewed as EVTs (Minieri et al. 2015). Feminist and multicultural practice, however, are not a-scientific; rather, the evidence upon which they rest does not always fit into an increasingly narrow definition of empirical evidence. I believe that this narrow definition of evidence and the concurrent increasing rigidity of techniques in psychotherapy are reflective of anxiety and fear in 
current Western culture, particularly among those with privilege, due to globalization and increasing complexity in society.

Anti-immigrant sentiments are rising in white America and Europe as boundaries become more porous and as societies become more diverse (Cochrane \& Nevitte, 2014). Neo-Nazi and white supremacy groups are using the term "white genocide" as a synonym for diversity to perversely frighten white people into blaming other racial groups for economic insecurity and changing social norms (Berger, 2016). This fear and anger in the white community is being accentuated even as white, Euro-American power hierarchies are imposed on the rest of the world. It is my contention that those privileged by discriminatory systems seek uniformity, control, and boundaries, because complexity, fluidity, and diversity, if genuinely embraced and practiced, undermine these systems. During this time of intense distress and uncertainty, it is important for psychologists and counselors to actively question whether therapy goals and methods are unwittingly participating in "colonialism writ small" in the therapy room. By this I mean that ideas of health and wellness that the therapist holds may not be beneficial to the well-being of clients if they equate with conforming to systems of inequality. Symptoms such as anger, depression, withdrawal, or even paranoia may be viewed as signs of mental illness, or may be viewed as normal, justified reactions to injustice (Sue, 2016). If therapists cannot discern the difference because they are not adequately familiar with the ways injustice can affect mental health, they run the risk of pathologizing normal, healthy reactions, and may even view learning to be calmer and quieter, or less upset despite injustice, as positive therapy goals, thereby undermining the mental health of their clients (Sue, 2016; Wendt, Gone, \& Nagata, 2015).

Another force leading to the narrowing of clinical approaches is the health insurance system in the United States. Brettschneider et al. (2014) and Rizvi (2013) asserted that insurance companies are interested in paying as little as possible, and this involves narrowing the focus of therapy to reducing specific symptoms for specific disorders rather than broader foci on personal growth, empowerment, improved relationships, and existential exploration. While EVTs and CBT are more medicalized than other approaches and thus more amenable to the demands of insurance companies, this does not mean they are producing superior outcomes. The outcomes and approaches deemed worthy of reimbursement might not match the outcomes and approaches that are most desired by clients.

To illustrate these ideas, I refer to the following case from my experience as a feminist supervisor in a Masters in Clinical Mental Health Counseling program. Feminist supervision (L. Brown, 2016), also referred to as feminist multicultural supervision (Arczynski \& Morrow, 2016), requires flexibility from both the supervisor and the supervisee as they engage in collaborative efforts to understand and address how systemic issues of power and discrimination may be affecting both the client and the dynamics in the room between supervisor and supervisee. My goal is to understand how my power, as a supervisor with evaluative authority, may inhibit my students from being the most creative and effective clinicians they are capable of, and to help them understand how similar dynamics may be entering their clinical relationships. Further, I encourage my supervisees to engage in dialogues that can empower their clients to recognize, 
challenge, and manage systems of oppression by engaging in similar conversations with my supervisees and drawing out the parallel processes. Through this process, I am striving to teach my supervisees how to bring social justice into the therapy room. Some of the details of the case have been altered to protect the identity of the client but the key aspects of the case are accurate.

\section{Case Example}

An African American female trainee expressed great frustration and concern about a client she was working with. Her client was an African American, single, female mother of three children, ages eight, five and two. The client was in therapy because she had recently lost custody of her children when she left them alone in her apartment to run to the market to get diapers for the two-year-old. She had decided to leave the children in the house because the youngest was sleeping and she did not want to wake him. She let the older two children watch cartoons and she left for what she thought would be a five-minute errand. Unfortunately, she was pulled over for speeding. When the officer asked her why she was speeding she told him her children were alone in the house so she was rushing home. The officer called child protection services for child neglect, and she lost custody of her children despite having no previous interactions with child protective services. The conditions for getting her children back involved attending a parenting training program and attending therapy. My student was assigned the case and she was frustrated because the client refused to comply with attending the parenting group. My student was being trained in EVT, cognitive-behavioral techniques and was carefully following the direction of her site supervisor. She had spent three sessions going over exactly what needed to happen to get custody, and affirming the clients' clear commitment to her children, and trying to build a plan with the client for compliance. The client, however, would not comply with the program because she felt the removal of her children was unwarranted because she was a good mother. She felt resentful that she was being forced to attend a parenting class and skeptical that she would be treated fairly in the system.

Below, I describe how adhering too narrowly to EVTs can undermine best practice, and conclude with a description of how feminist and multicultural practices offer valuable solutions even when they are difficult to measure with traditional tools of empiricism. The resolution of the case is presented at the end with suggestions for clinical work and training.

\section{Defining Evidence}

Empirically validated therapies are ideally a way to protect clients from ineffective therapy at best and harmful quackery at worst (Samuels, 2008). Empirical evaluation is an important component of safeguarding the public and an attempt to take researchers' biases out of the outcome research. Many have effectively argued, however, that pure, bias-free empiricism is rare, or even impossible (Fine, 2012; Kirmayer, 2012; Pederson, 2003; Woolfolk \& Richardson, 2008). Even in the hard sciences, observer bias has been well documented (Elliott $\&$ Resnik, 2014; McComas, 2010), and there is ample evidence that it affects psychological science as well (Cushman, 2012; Norcross \& Lambert, 2011; Prilleltensky, 1989; Woolfolk \& Richardson, 2008) including neuroscience (Parvisi, 2009). As Cushman (2012) noted, psychological science is "a 
good example of the hermeneutic contention that, in the human sciences, prejudgments cannot be bracketed off or erased; they can only be disguised" (p. 263). In other words, the questions asked, the variables deemed important, and the way results are interpreted will all reflect the world-view of the researcher.

The above case demonstrates the failing of manual based EVT in a situation when social and political contextual factors are not accounted for. Outcome goals that are rooted in the client's assessment of their dilemmas and issues, rather than the clinician's re-definition of their dilemmas and issues, are often extremely difficult to quantify and therefore more difficult to study empirically. Despite thousands of articles written about the role of social justice in clinical work, I was not able to locate studies with social justice awareness or social activism skills as a measured therapy outcome variable. Social justice-oriented treatments that focus on the whole person in their lived context, rather than a narrowly defined presenting issue or set of symptoms, have not been studied as extensively because this type of treatment is much harder to quantify and compare. However, there are a growing number of studies demonstrating the benefits of treatments not on the list of EVTs such as psychodynamic (de Maat et al., 2009; Grande et al., 2006) and humanistic (Elliott, 2002; Shechtman, \& Pastor; 2005). Thus, it is important to ask why some studies are being given precedence over others, and what fuels the current discomfort with other forms of therapy?

Feminist scholars have noted that missing from research on EVT's are questions about how culture shaped psychologists' and counselors' current methods of diagnosing (the DSM), racial and ethnic variation in the manifestation of certain diagnoses, etiology of observed symptoms, and what is considered a positive outcome (L. Brown, 2010; Fine 2012). Yet, all these components of EVT have been demonstrated to vary between cultures (Paniagua, 2013; Pearce, 2014). Further, most EVTs are based on theoretical orientations that were developed within the dominant cultures of the United States and wealthy European countries (Moir-Bussy, 2012; Sue \& Sue, 2012). The conceptualization of health and illness, as well as the norms about treatment therefore reflect white, middle class, male-dominated standards. This does not mean EVT treatments are not useful, but it does mean that they, like all other psychotherapy approaches, are culturally bound. One of the repeated arguments made against the EVT movement is its failure to attend to social injustice and power differentials (Fine, 2012; Nebelkopf et al. 2011; Samuels, 2008).

Proponents of EVTs use medicine as the ideal comparison for psychotherapy (Norcross \& Lambert, 2011). The more psychotherapy can claim to be like medicine, with exact diagnoses and specific, invariant treatment methods, the more power practitioners' gain in terms of reimbursement from insurance companies and obtaining grant money (Fine, 2012; Henry, 1998; Norcross \& Lambert, 2011). This is a faulty comparison, however, because there are many variables that impact psychological functioning: parents, siblings, cultural norms, gender roles, developmental processes, traumas, losses, achievements, friendships, education, economics, social and political forces, biological predispositions, etc. This staggering variation in human experience means that even though therapists may be able to find a diagnosis that 
approximates a client's symptoms in the ever-changing versions of the DSM, the factors that led to the diagnosis will vary, probably widely, between clients with the same diagnoses. In other words, even if a therapist can match a client's symptoms to a diagnosis in the DSM, they may still know very little about the etiology of those symptoms, the cultural meaning and impact of those symptoms, or what a positive outcome would be for the treatment of those symptoms. As Brown (2010) argued,

Any feminist epistemology of identity will take two factors into account. The first is the presence of multiple social locations in the life of each person and the attendant combination of privilege and disempowerment stemming from each of these. The second is that these experiences will interact in a variety of manners and that there is not one, but a multiplicity, of trajectories of identity development that can lead to good function and/or distress and dysfunction (pp. $72-73$ ).

If diagnosis cannot explain how a psychological problem developed, why would one therapy approach fit all clients with that diagnosis? Further, how can a therapist engage in social-justiceoriented practice if the ideas about health and behavior embedded within their approach overlook the impact of injustice on the presenting issues and fail to make room for cultural variation in desired outcomes?

\section{Culture and EVTs}

All psychological theories reflect the cultural and historical contexts within which they were developed; which were, for the most part, white, middle class cultures (Brown, 2006; Cushman, 2013, 1995; Pedersen, 2003; Sue \& Sue, 2012). Multicultural and feminist scholars have written extensively about how dominant psychological theories have often alienated people of color and women by presenting the white male norm as healthy, and all other ways of being as pathological (Brown, 2006: Heesoon, 2009; Sue \& Sue, 2012). To be culturally competent, scholars argue for the necessity of widening the scope of one's practice, broadening one's conceptual understanding of what is and is not considered healthy or abnormal, and being willing to be flexible in one's approach to accommodate multiple worldviews (Brown, 2016; Heesoon, 2009). Feminist psychology urges practitioners to demonstrate humility about our psychological knowledge and to be aware that our relative power as expert in the therapy relationship can lead to a perpetuation of the status quo (Brown, 2010). As Brown (2010) stated,

Feminist therapy does not simply study the "other" in order to offer a neutral perspective on that experience. Rather, what is inherent in feminist therapy is the radical notion that silenced voices of marginalized people are considered to be the sources of the greatest wisdom. This is a shifting of the value of knowledge claims from those of culturally appointed experts to the expertise of the oppressed (p.2).

Fine (2012) noted that the research supporting EVTs not only values the judgments of the privileged over the experiences of the oppressed, but in so doing, often narrows the scope of 
psychological support in poor communities because the evidence of effectiveness cannot be demonstrated through the narrowly defined avenues of evidence gathering. Programs that support oppressed people have a harder time demonstrating effectiveness because the concerns of their clientele are often a confusing mix of poverty, discrimination, and other sociopolitical factors interlaced with the more traditional interpersonal symptoms described in the DSM. Because of this increased complexity within the problems being addressed, therapeutic goals are both harder to succinctly define and take longer to achieve. In this way EVTs, in attempting to find uniformity in techniques that are very much entwined with DSM diagnoses, are in danger of failing marginalized populations (Samuels, 2008, Woolfolk \& Richardson, 2008).

The case above illustrates this difficulty. The diagnosis was essentially that the client was a neglectful mother (not an actual diagnosis, but the problem as presented in therapy). From the client's perspective, however, the problem was racism. I shuddered when I heard the client's story because I can imagine making a similar decision to quickly rush out for an urgent errand with my kids at home. I doubt, however, that I would ever actually lose custody of my children over one such incident, because I am white, middle-class, and am part of a traditional family of two, heterosexual parents. What my student and I realized was that the stated therapeutic problem was itself problematic and biased. Then we had to examine if the traditional treatment approach would adequately address the real issue, that of social injustice - of having to comply with a plan that implies one's inadequacies and failures, and is a reinforcement of racist and classist hierarchies. The client had to decide to endure humiliation because the stakes were high - her children - but she could not bring herself to do so unless someone could witness the injustice.

\section{The Problem of "Adaption"}

Proponents of EVTs have posited that they can be "adapted" to various cultures (McKleroy, et al. 2006). Indeed, there are many articles that use the language of "adapting" EVT's to one culture or another (Bernal, Jimenez-Chafey \& Domenech Rodrigez, 2009; Hwang, 2009). In my view, however, the notion that one would have to adapt a treatment is antithetical to the idea of uniformity. EVPs cannot be viewed as universally effective if a process of "adaption" must occur to make them appropriate for certain cultures. What appears to be lurking underneath the word "adapt" is the assumption that this treatment works among the dominant culture where it was developed (white, Euro-American, middle class), and as an afterthought, it can be bent to fit others (any cultural group that is not middle-class, Euro-American). As Díaz-Lázaro, Verdinelli, and Cohen (2012) pointed out, EVTs tend to be more effective for those who are privileged and less effective for those who are oppressed, thus the need to adapt them. In addition, adapting EVTs for different cultures will only be temporarily useful because culture is fluid and changes with time. Especially in the era of globalization, cultural norms are changing rapidly in many societies and so what may work with a specific population at this point in time may not be effective at all with the same population in the future. 
Wampold and Imel (2015) offered a way to continue researching what makes therapy effective while also making room for a wide variety of worldviews and approaches by focusing on common therapeutic factors. For instance, a positive therapeutic alliance has been found to be the most important factor in positive psychological outcomes. A strong therapeutic alliance is a measurable outcome, but it is also a flexible outcome. How to effectively connect with a client will be unique for each client. Taking culture and context into account will enhance the therapeutic connection with diverse clients (Rogers-Sirin et al., 2015) and contribute to positive therapy outcomes. Wampold and Imel (2015) made it clear that empirical research and critical thinking regarding therapy and culture are not mutually exclusive. The focus on common therapeutic factors does not require "adaption" because there is enough flexibility in the concepts to make room for the uniqueness of each therapist, client, and therapeutic relationship.

\section{Globalization, Anxiety, and the Rise of EVT}

What is it about this current point in history that has supported the EVT movement? I am asking not about the desire to find effective treatments, which is an important and central goal, but rather the narrow view of how to judge effectiveness and the push to make psychotherapy uniform. It is my belief that globalization and modern technology are leading to a specific type of anxiety among privileged groups that is reflected in current psychotherapy trends.

Throughout human history, most people stayed within societies of those who shared their cultural norms and practices. Today, however, it is nearly impossible to insulate oneself from cultural differences. Travel is more common, and immigration is on the rise. Even when we are not physically moving between cultures, the media, which is increasingly dominant in modern life, exposes us regularly to multiple religions, nationalities, sexualities, and other identities. While many people view this development as wonderful, there is no denying that it has caused conflict and anxiety (Salzman, 2006; 2008). As Woolfolk and Richardson (2008) stated,

There is a 'dark side' to modernity chronicled thoroughly by sociologists from Weber to Berger: the 'disenchantment' of the world, the loss of community, the end of a self-evident consciousness' of the industrialized West is a world-view beset with dilemmas and malaises not found in primitive and traditional views of reality (p. 54).

Although these forces can cause anxiety at every level of hierarchies of power, it is my contention that those who hold privilege and power in modern Western culture are more likely to affect the lives of those with lesser power as they manage their anxiety. As exposure to multiple cultures increases, one possible means of relieving anxiety is to seek ways to minimize or deny the confusing variety of cultural differences. As Woolfolk and Richardson (2008) noted,

The worldview of modernity is dominated by science and scientific technology and the modes of thought peculiar to them. It is rooted in the ideal of progress, a faith in the power of human abilities to be equal to any problem, the quest for certitude, and a devaluation of the traditional past (p. 54). 
In my view, not only is the traditional past devalued, but also are the strengths of diverse perspectives, as the worldview of the privileged is put forward as normal and healthy. Those who hold positions of privilege influence which cultural norms are more likely to be viewed as normal, healthy, and functional. People whose cultural values do not line up with the dominant culture can be harmed in therapy if they are made to feel that there is something unhealthy about their worldview (Wendt, et al., 2015). Wendt, Gone and Nagata (2015) noted that, for the most part, this type of potential harm, which has been widely described by multicultural and feminist therapists for decades, has largely been left out of the body of research into harm in therapy.

Within clinical and counseling psychology, the push for conformity of practice can be seen in the increasing size of the DSM. As more clinical knowledge is gathered and difficulties with drawing clear lines around vague mental distress are voiced, definitions and means of distinguishing one type of issue from another are forced to widen. Rather than moving away from the idea that mental illnesses are clear and cleanly distinguished from one another, the manual adds more and more labels to try to account for behaviors that did not fit smoothly into previous versions of the DSM. Similarly, this desire for simplicity is reflected in the field's efforts to find uniform, predictable ways to help people overcome psychological distress. This is a noble cause, but uniformity and predictability are not always possible. If psychologists and counselors ignore this reality or try to smooth the complexity away, marginalized and oppressed populations will most likely be poorly served, or even harmed.

Generally, EVTs represent treatments that have been demonstrated to be empirically more effective than no treatment, or an alternative treatment, among a group of research participants who have been selected based on a tightly defined type of disorder, and who usually reflect the dominant and/or privileged culture, at this point in history (Kirmayer, 2012; Woolfolk \& Richardson, 2008). This means that the EVT research offers little to no information about people who did not respond to treatment, or people who were not selected for those experiments. This research (like all social research) can only tell us about rates of responsiveness in a particular culture and time in history. As culture shifts and changes, it is possible, even probable, that how populations respond to a given treatment method will change. The EVT research cannot, and never will, tell clinicians what will work for all clients from all different backgrounds, at any point in time.

Woolfolk and Richardson (2008) have noted that, as the DSM has moved away from a theoretical stance, the EVT movement has also become less theoretically grounded and has become "little more than product testing" (p. 69). Theories of thought that point toward greater ambiguity, greater uncertainty, and greater complexity are being pushed to the edges, while theories that appear to be more linear and uniform are being bolstered.

The desire to pinpoint concrete ways to be happier and healthier seems to make sense on the surface, but on closer look, this effort can also be viewed as reflecting a culture where there is 
little tolerance for emotionality, especially for vulnerable and painful emotions. In most EVT techniques, emotions other than positive emotions are viewed as something to be controlled or removed (Miller, 2008; Stocker, 1996). Too much grief is now seen as a disorder (Wakefield, 2013) and anger as a useful tool to harness for the cause of social change is invisible (Lorde, 1981). For instance, recent research has found that religious people tend to be happier (Ferriss, 2002; Green \& Elliott, 2010). This empirical evidence is presented with no discussion of whether this is true for people who are marginalized by religion. Are gay people whose religion teaches they are sinful happier in religion? Are women whose religions teach them to obey or submit to men happier in religion? In such situations, is happiness a more important emotion than anger, grief, or sadness? Results like these can be interpreted as "those who benefit from the status quo, are happier than those who do not." This reflects what makes privileged people happy, rather than a universal truth about happiness in general.

\section{The Costs of Narrowing Theoretical Approaches to the Field and to Clients}

What does this unnecessary tension between EVT's, CBT, and other theoretical orientations cost us as a field? What is the damage to psychology and counseling, and to the people who seek psychological treatment? One potential cost is that it may lessen effectiveness of psychotherapy because it may lead counselors and psychologists to avoid spontaneity and experimentation in the therapy room. Psychological treatment should, of course, be informed by empirical evidence, but it should also be informed by the therapist's experience, personal insights, and willingness to learn from each individual client. This is essentially the tension between anecdotal and empirical evidence. Outcome research generally reports on averages across populations; it does not tell much of anything about how any given individual may react to treatment. Effective clinicians understand that it would be damaging to their practice to ignore their experiences of what does and does not work for them personally in the therapy room, and how particular clients receive specific types of intervention. Cookbook approaches to therapy run the risk of dissuading clinicians from being creative and flexible when providing services.

Despite the lack of focus on client contributions to successful outcomes in the EVT research, there is a growing body of empirical evidence which indicates that what the client brings to therapy is one of the most important contributors to success (Bohart \& Tallman, 2010; Orlinsky, Ronnestad, \& Willutzki, 2004). Bohart and Tallman (2010) noted that many people find healing and change without psychotherapy and within therapy the degree of client involvement and the nature of client participation has been repeatedly demonstrated to be essential to outcome. The recommendations that Bohart and Tallman (2010) suggested, based on the research into client contributions to therapy, are perfectly aligned with the core components and values of feminist psychology. For instance, Bohart and Tallman (2010) recommended that therapists enlist and promote client strengths, resources, and personal agency. Brown (2004) stated that the symptoms a client brings to therapy reflect the strategies which they have found to survive and cope with social and political oppressive forces and that these symptoms should be reframed as such. Brown (2004) noted that clients are not only motivated to change, but are the experts on their own needs and best positioned to find the path that will most effectively empower them. Finally, Bohart and Tallman (2010) stated that therapy should be viewed as a collaboration, 
which is the central value of feminist psychologists and counselors who have also paid attention to how power affects this collaboration. Although feminist therapy would seem to be particularly appealing to many because of its attention to collaboration and empowerment, it has been largely absent from the professional debate on EVTs.

The increasing marginalization of many theoretical orientations is seeping into the public perception of psychotherapy. In 2013, for example, an article was published in the New York Times titled "Looking for Evidence That Therapy Works" (Brown, 2013). In this article, the author made the case that if your therapist is not practicing EVT based on CBT they are providing substandard care. The New York Times article was overly simplistic in its assessment of the current research on psychotherapy, and did not cite studies published in reputable psychology journals demonstrating effectiveness of a variety of theoretical orientations (de Maat et al., 2009; Elliott, 2002; Grande et al., 2006; Shechtman, \& Pastor, 2005). This type of misperception about psychotherapy reflects the current tendency within the fields of clinical and counseling psychology that currently devalues diverse orientations. Psychologists and counselors would better serve the public by sharing that there are multiple types of psychotherapy available and clients should think about what would be most suited to them given their personal needs.

EVTs can be extremely valuable for targeted interventions for specific symptoms, but even the most robust findings have not demonstrated absolute effectiveness. Clients need to know that there is still hope if they do not find relief with CBT. Further, clients do not always (or often) come to us with one diagnosable condition. Clients often present with more abstract experiences of feeling beaten down by the stress of poverty, coping with discrimination, searching for a sense of racial or ethnic identity, or more abstractly, grappling with life questions that do not fit neatly into DSM diagnoses (Harper, 2013; Swartz, 2013). Even when they do fit into DSM diagnoses, EVTs tend to conceptualize and treat these symptoms at an individual level despite ample evidence that they are often normal reactions to societal ills and thus individual level treatment is likely to be limited in effectiveness.

The therapy room is particularly vulnerable to what Fine (2012) described as the "privatization of public troubles" (p. 5). Psychotherapists meet with individuals, couples, families, or small groups and so it is easier to see individual and micro-level contributors to pain. Attending to culture or social-level contributors to suffering requires one to connect a unique experience in an intimate setting to broader, historically situated information about the ways women, people of color, and economically disadvantaged people are harmed by systematic injustice. For example, understanding that the mass incarceration of people of color and brutal police tactics in poor neighborhoods are unjust is easier to understand and discuss outside of therapy. In therapy, the client may not know that their symptoms are connected to fear about being harmed by the police or discriminated against in society. Another possibility is that the client does see this connection but is afraid the therapist will not and therefore does not feel safe to discuss it, as was the case with the client in this case example. Social justice-oriented practice, on the other hand, would require that the therapist explicitly make room to discuss these systems of oppression in order to connect the individual client's suffering to larger, societal forces (Brown, 
2004, 2006, 2016). By doing this, clients are less likely to internalize negative stereotypes and are more likely to feel connected to others who are also affected by these forces, thereby reducing feelings of isolation and despair (Brown, 2004; Crethar, Rivera, \& Nash, 2008; Hoffnung, 2005). Ideally, the client will develop strategies for resistance at the personal and societal level, because this type of conversation expands the power to resist oppression for both client and counselor. Brown (2004) described these conversations as "Subversive Dialogues" in her brilliant book of that title. Returning to the case, I suggest ways to counter these homogenizing forces within the field and incorporate social-justice into supervision and treatment through feminist techniques.

\section{Case Conclusion}

Feminist and multicultural scholars have repeatedly emphasized the importance of challenging sociopolitical realities in the practice of therapy (Brown, 2016; Heesoon, 2009), but doing so is difficult. Looking for universals and uniformity makes the job of counselors and psychologists much easier, at least on the surface. Diagnosing symptoms in an individual is easier than trying to connect symptoms to wider sociopolitical forces. Using clearly defined techniques is easier than engaging in emotionally charged conversations about social injustice. In this way counselors and psychologists are easily recruited to the role of maintaining the comfort of the privileged. To avoid this possibility, I employed feminist multicultural supervision techniques to try to bring my student's instincts and insights about this case to the forefront.

Upon hearing the details of the case, I sensed that my student, like her client, was angry about the injustice of the situation. I also believed that, had her client been white, her children would not have been removed. This may not be the case, but I wondered if my student and her client also felt racial bias was a component of this case. Further, I wondered if my identity as a white professor (privileged by race and status) prevented my student from sharing these concerns. To address this possibility, I asked my student if she had thought about the fact that racial bias might have contributed to the decision to remove the children. She confirmed that she did think so, and we discussed recent events of police violence toward black people and her own personal experience of being over-surveilled by police. I then invited her to consider the possibility that her client needed someone to understand this aspect of her case, to be a witness to the racial injustice she was experiencing before she could comply with the parenting training. Together we wondered if her client would be able to comply if she had someone in the system that knew that she was a good person and a good mother and that she had been wronged.

During our conversation, it became clear that my student already sensed the central dilemma, but worried that the type of conversation I was suggesting was not legitimate psychotherapy and would not be acceptable. My student was using techniques that have been shown to be very effective with many clients, and she was frustrated that they were not working with this client. Our discussion, and later her discussion with her client, demonstrated that a large part of the problem was that the techniques she was using reflected the ideas of those with power about a good outcome. The police, child protective services, and the agency where the studentcounselor interned, may had the best of intentions, yet their interactions with the client did not reflect her needs or her lived experience. All three of these agencies required compliance with 
the treatment program before she could regain custody of her children. Compliance appeared to the client to require that she acknowledge that she had neglected her kids and therefore needed to learn how to parent, and she was unwilling to go along with this. My supervisee sensed that she needed someone to hear her outrage at being deemed a bad mother, hear her view that racism had affected the decisions of the officer to report her, the child protection services decision to take her children, and the counseling agency's insistence that she comply. When the student-counselor stepped away from the narrow goal of treatment compliance and instead prioritized validating the client's reaction to social injustice, a path to family reunification opened.

My goal as a supervisor was to empower my student to trust her instincts and the wisdom she possessed as a clinician. We discussed how her concern about what was legitimate therapy was preventing her from making a more genuine connection with her client. We also discussed how my role as a supervisor and professor, and my identity as a white woman, made it intimidating for my student to talk about the social and political issues affecting this case. She had learned that this type of conversation was not part of the academic protocol, as described by Sue (2016), wherein academics profess to value diversity and equality, but avoid the tough conversations that occur when power, such as white supremacy or misogyny are challenged openly. As a supervisor, I had to be explicit in inviting this type of conversation to demonstrably counter the academic protocol.

My student reported a week later that she and her client had a very intense and productive session in which her client discussed racism and how racial injustice were affecting her family. My student happily reported that her client had begun attending class and was on track to regain custody of her children. In this case example, the client's anger was initially seen as preventing her from complying. My student was frustrated with her refusal to follow simple steps to get her children back. My student was particularly distressed by this because she believed the client to be a loving and caring mother. Only when she could honor the client's anger, rather than trying to convince her to control it, did therapy become effective. The client's anger was justified, and by simply controlling it, the client felt she would have had to lose an important part of herself, the part that knew she was a good mother, the part that knew she had been abused by the system. When my student lifted up her client's anger, validated it, even cherished it, the client could endure the humiliating process of submitting to parenting classes to regain custody of her children.

\section{Recommendations for Action}

\section{In academia}

Taking action in academia can be anxiety provoking, especially for untenured faculty, particularly for faculty who already cope with the threat of marginalization due to gender, ethnicity, race, immigration status, sexual identity or orientation, able-ism, and other aspects of identity. Untenured faculty might look for supportive colleagues and mentors, and get a feel for how their respected chair, dean, and others in authority view psychotherapy and various theoretical 
approaches. Tenured faculty are in a better position to work within their departments to make sure there is room and respect for various theoretical approaches and create spaces for junior colleagues to take part in these efforts. Many counseling and psychology programs, particularly counseling psychology programs, have identified social justice as a core value. This can serve as a launch pad for dialogues about the narrowing definitions of empirical evidence and increasing marginalization of certain approaches within academia. Regardless of the core values of any given department, however, it is likely that broaching topics that question or challenge the increasing dominance of CBT and marginalization of other theoretical orientations could be met with avoidance and evasiveness, particularly when themes of social injustice are broached. As Sue (2016) noted, when discussing social justice and cultural competence in an evaluative setting such as academia, multiple perspectives and overlapping concerns can lead to incredibly complicated and emotionally draining encounters. For an excellent overview of this phenomenon and suggestions for dealing with this type of conversation see Sue's (2016) book, Race Talk and the Conspiracy of Silence. The emotionally fraught nature of these conversations can be intense that professors and supervisors may choose to avoid them out of personal discomfort or fear of professional repercussions, and yet they are essential in any program that takes social justice seriously. Psychologists and counselors must be willing to cope with the pain and discomfort that genuine change so often requires if they are to make any real progress towards social justice within their professions.

In my experience, students and professionals alike, especially white students and professionals (myself included), will genuinely and quickly affirm the values of acceptance and respect for cultural differences until something challenges their perceptions of themselves as supporting these values in their own actions. When clients, students, or professionals try to point out inequality, marginalization, or discrimination within institutions of learning, friendships, professional relationships, or clinical work, the conversations can quickly become defensive and hostile. I am increasingly convinced, however, that this is where the most important learning and changing occur. The ugly imprint of racism, sexism, heterosexism, able-ism, xenophobia, and other forms of oppression make their way into classrooms, relationships, and therapy rooms, even when participants abhor these social forces, because we are all part of society and these forces are deeply embedded in society. This also means that these forces are embedded in theories of psychotherapy (Cushman, 1995). Psychologists and counselors must be willing to let social action change them personally, not view it as a project to engage with professionally. When the lens is turned onto our own lives and institutions by a client who resists treatment, a student who shuts down, a colleague who isolates or faces unjust consequences because of bringing social justice into their work, it is an opportunity to learn and grow and change. The ideal response is to listen, take the feedback seriously, and incorporate it into more just and equitable work. This is one important way that the private and the political connect in psychology and counseling.

\section{As teachers}

In the classroom, there are many opportunities to encourage students to engage in critical thinking about the cultural implications of theories of psychotherapy. Class exercises can be 
used to help students identify their subjective positions and assumptions. For example, students could spend time free writing about what they believe mental health involves, what healthy and unhealthy relationships look like, what types of relationships and conversations have helped them through crises, etc. This could be followed by discussions with other members of the class for comparing and expanding notions of health, illness, and helping. Helping students understand that psychotherapy is a value-laden practice, and to accept the subjective aspects of psychotherapy, is preferable to striving for the unobtainable goal of clinical objectivity, which can lead to confusing one's own notions of mental health with an imaginary universal notion of mental health. This type of self-reflection is a skill that should be taught and encouraged in training programs, and given equal importance to other basic counseling skills.

\section{As supervisors}

As recommended by Brown (2016), supervision should include conversations about power hierarchies and how they affect supervision and treatment. Supervisors should explicitly name these issues and invite students and supervisees to engage in these conversations, because students may be afraid to initiate them (as my student was). There is no simple conclusion to this type of conversation, because there are inherent power differentials in both types of relationship. Reframing the power differences in terms of what types of knowledge and experience each party brings to the supervision or therapy dynamic can be very helpful. The supervisor likely has more knowledge and experience about therapy, but students and clients have more knowledge about their lived experiences and the contexts where their psychological distress occurs. Bringing these sources of knowledge and experience together in mutual respect can enhance creative and effective outcomes (Brown, 2016).

At the College of Staten Island, City University of New York (CSI CUNY), the master's degree in clinical mental health counseling was faced with the question of how we should put our social justice orientation into practice for the residents of Staten Island after news that the officers who killed Eric Garner were acquitted. Many students and faculty were devastated, and many of the clients our students were working with were too. Our faculty facilitated many difficult conversations about the justice system in America and the effects that racial bias on the police force can have on families on Staten Island. We discussed mass incarceration, the fear of the police among many people of color, the data about differing, more punitive sentencing for people of color, and how white privilege can cause white counselors to miss the importance of these factors. It was from these conversations that we began to realize we needed to include community action in some form into our curriculum. This process is still evolving, but feedback from students about what they were experiencing both as therapists and in their own lives has helped us move our program toward more concrete action related to social justice. For example, our students will be mentoring at-risk students during their first year, before they begin their practicums, and we have launched a research project in collaboration with low income residents of Staten Island with the eventual aim of identifying how social activism can contribute to improved mental health for marginalized populations. This project is described below. 


\section{As researchers}

There are examples of clinical researchers who are finding effective ways to conduct outcome studies with social justice oriented work. Minieri and colleagues (2015), for example, described a method of using client feedback to assess the effectiveness of social-justice-oriented practice by using the partners for change outcome management system (PCOMS). The PCOM was designed by Duncan (2012) as a means of obtaining client feedback on their therapeutic experiences quickly, thus measuring therapy effectiveness in a fairly simple way. As Minieri et al. (2015) noted that the PCOM is one of several ways to obtain client-level data about therapy effectiveness that could be used with a variety of therapeutic orientations. These alternative ways of obtaining outcome data could be used to widen the field's notion of what constitutes evidence of effectiveness.

Wendt et al. (2015) suggested that idiographic research offers an important means of investigating the potential harm ethnocentric psychotherapy can cause to diverse clients. They suggested case analyses, with a specific social justice frame, can help identify the ways that a therapist's actions in therapy may affect clients. Critical Participatory Action Research (CPAR) is another approach to research that takes specific steps to avoid imposing the researcher's cultural frame onto participants (Stoudt, Fox, \& Fine, 2012). The CPAR approach to research requires that the participants, or some representative sample of the participants, are also coresearchers, meaning every aspect of the research, from goals, to methods, to means of interpretation and dissemination, are generated and executed by members of the population in the study. In applying CPAR to outcome studies, the clients and therapists involved in any study would participate in identifying how to measure successful treatment and what types of therapy should be offered and assessed. Chou et al. (2016) noted that CPAR is not well understood or utilized in clinical or counseling psychology. They suggest an approach for applying CPAR to outcome research called Participatory Critical Incident Technique (PCIT). They worked with youth to evaluate a program at an alternative school for vulnerable youth using PCIT.

Chou and colleagues (2016) described how the youth became increasingly aware of how social and political forces, such as racism, contributed to their experiences and were involved in creating changes in the school based on their growing awareness as the research progressed. At CSI CUNY, we are in the beginning phases of a CPAR project investigating the types of mental health services available to low income residents of Staten Island, what types of services would be most beneficial, and how a collaboration between the community and the college can work toward greater social justice activism for the well-being of the community. The types of services are being identified and created by both clinicians and the residents who will be utilizing them. This collaboration will help create mental health services that are specifically designed for lowincome residents of Staten Island, that will include a variety of both traditional and new, neighborhood-specific services, and that will be offered by both mental health clinicians and community members who support mental health in other ways. Although the project is in the beginning phases, it has already become clear that addressing inequality, discrimination, and oppression must be integral to the programs offered or they will not genuinely address what community members view as major factors in their mental health. 


\section{As members of professional organizations}

One important action step is to get involved with professional organizations and make the case for widening the field's conceptions of legitimate science, and legitimate practice. Activism within professional societies and on college campuses may take many forms such as running for leadership roles, joining or forming committees that address related topics, mentoring student activism groups, or in some cases, leaving organizations in protest. Pope's (2008) very powerful letter resigning from APA over the torture scandal is an excellent example of this. The creation of Counselors for Social Justice, a division within the American Counseling Association, provides another great illustration of an organizational social change effort. Their mission is

"...to work to promote social justice in our society through confronting oppressive systems of power and privilege that affect professional counselors and our clients and to assist in the positive change in our society through the professional development of counselors." (from website, https://counseling-csj.org/)

Their webpage provides resources to counselors and other mental health professionals for incorporating social justice into their practice. Another example is the More Pie initiative within APA's Division 17, a group that works toward greater social justice within the profession of counseling psychology and serves as an example of working toward social justice within professional organizations (Fouad, Gerstein, \& Toporek, 2006). The More Pie initiative refers to trying to increase the resources available for all, rather than competing for limited resources, a situation that pits groups against each other rather than fostering collaboration. The More Pie initiative has influenced many conferences, publications, and community initiatives that have helped steer the direction of Division 17, and psychology in general, toward greater social justice.

\section{Conclusion}

The current emphasis on EVTs is coming from a desire to improve patient care, which is a noble goal, but it is being pursued in a culturally narrow frame. The desire for psychotherapy to be more like medicine, with clear diagnoses and specific, universal interventions, has led to the dominance of CBT, which lends itself more easily to conventional outcome studies, but runs the risk of reifying a power hierarchy that is harmful to marginalized groups. To adequately ground therapy in the sociopolitical realities of clients' lives, I believe counseling and psychology need to embrace the creative and personal aspects of psychotherapy rather than viewing them as unscientific, even though these aspects are harder to measure and manualize. Good therapy is informed by available empirical inquiry, but it is also deeply dependent on each clinician's unique relational and empathic skill, the flexibility of their thought processes, and their willingness to embrace the infinite variety of the human experience, with all the confusion, messiness, and suffering, as well as the intense beauty and meaning that it holds. 


\section{Author Contact Information}

Correspondence regarding this article should be directed to: Dr. Lauren Rogers-Sirin, The College of Staten Island: City University of New York, 2800 Victory Blvd. 4S rm. 233. Email:

lauren.rogerssirin@csi.cuny.edu

Dr. Rogers-Sirin earned her MA and Ph.D. in Counseling Psychology from Boston College. She is a licensed psychologist who practices from a cultural-relational model of counseling. She has clinical experience with clients of all ages and with a broad range of mental health issues but the bulk of her experience has been with young adults on college campuses. She uses her clinical experience to enrich the courses she teaches and inform her scholarly work. She believes strongly in the researcher-practitioner model and believes research and clinical work should inform and shape each other. Her research interests all relate to issues of social justice in the counseling profession, including the experiences of immigrants in counseling, attitudes towards psychotherapy among Muslim Turks, the cultural values inherent in theories of psychotherapy, and the intersection of social justice and mental health.

\section{References}

Arczynski, A. V., \& Morrow, S. L. (2017). The complexities of power in feminist multicultural psychotherapy supervision. Journal of Counseling Psychology, 64, 192-205. doi:10.1037/cou0000179

Berger, J. M. (2016). The Turner Legacy. The International Center for Counter-Terrorism, The Hague. Retrieved from https://icct.nl/wp-content/uploads/2016/09/ICCT-Berger-TheTurner-Legacy-September2016-2.pdf

Bernal, G., Jiménez-Chafey, M. I., \& Domenech Rodríguez, M. M. (2009). Cultural adaptation of treatments: A resource for considering culture in evidence-based practice. Professional Psychology: Research and Practice, 40, 361-368

Bohart, A. C., \& Tallman, K. T. (2010). Clients: The neglected common factor in psychotherapy. In B. L. Duncan, S. D. Miller, B. E. Wampold, \& M. A. Hubble (Eds.). The heart and soul of change: Delivering what works in therapy, $2^{\text {nd }}$ edition. (pp. $\left.83-111\right)$. Washington, DC: American Psychological Association.

Brettschneider, C., Djadran, H., Härter, M., Löwe, B., Riedel-Heller, S., \& König, H. H. (2014). Costutility analyses of cognitive-behavioural therapy of depression: A systematic review. Psychotherapy and psychosomatics, 84, 6-21.

Brown, H. (2013). Looking for evidence that therapy works. The New York Times, 4.

Brown, L. S. (2004). Subversive dialogues: Theory in feminist therapy. New York: Basic Books.

Brown, L.S. (2006) Still subversive after all these years: The relevance of feminist therapy in the age of evidence-based practice. Psychology of Women Quarterly, 30, 15-24. 
Brown, L. S. (2010). Feminist therapy. Washington, DC: American Psychological Association.

Brown, L. S. (2016). Supervision essentials for the feminist psychotherapy model of supervision. Washington, DC: American Psychological Association.

Chou, F., Kwee, J., Buchanan, M., \& Lees, R. (2016). Participatory critical incident technique: A participatory action research approach for counselling psychology. Canadian Journal of Counselling and Psychotherapy, 50, 51-74.

Cochrane, C., \& Nevitte, N. (2014). Scapegoating: Unemployment, far-right parties and anti-immigrant sentiment. Comparative European Politics, 12, 1-32.

Counselors for Social Justice. (August 28, 2017). Retrieved from https://counseling-csj.org/

Crethar, H. C., Rivera, E. T., \& Nash, S. (2008). In search of common threads: Linking multicultural, feminist, and social justice counseling paradigms. Journal of Counseling \& Development, 86, 269-278.

Cushman, P. (1995). Constructing the self, constructing America: A cultural history of psychotherapy. Reading, MA: Addison-Wesley.

Cushman, P (2012). Defenseless in the face of the status quo: Psychology without a critical humanities. The Humanistic Psychologist, 40, 262-269.

Cushman, P. (2013). Because the rock will not read the article: A discussion of Jeremy D. Safran's critique of Irwin Z. Hoffman's "Double thinking our way to scientific legitimacy." Psychoanalytic Dialogues, 23, 211-224.

de Maat, S., de Jonghe, F. Schoevers, R., \& Dekker, J. (2009). The effectiveness of long-term psychoanalytic therapy: A systematic review of empirical studies. Harvard Review of Psychiatry, 17, 1-23.

Díaz-Lázaro, C. M., Verdinelli, S., \& Cohen, B. B. (2012). Empowerment feminist therapy with Latina immigrants: Honoring the complexity and socio-cultural contexts of clients' lives. Women \& Therapy, 35, 80-92.

Duncan, B. L. (2012). The Partners for Change Outcome Management System (PCOMS): The Heart and Soul of Change Project. Canadian Psychology/Psychologie Canadienne, 53, 93104.

Elliott, R. (2002). The effectiveness of humanistic therapies: A meta-analysis. In D. J. Cain (Ed.) 
Humanistic Psychotherapies: Handbook of Research and Practice (pp. 57-81). Washington, DC: The American Psychological Association.

Elliott, K. C., \& Resnik, D. B. (2014). Science, Policy, and the Transparency of Values. Environmental Health Perspectives, 122(7), 647-650. http://doi.org/10.1289/ehp.1408107

Ferriss, A. L. (2002). Religion and the quality of life. Journal of Happiness Studies, 3, 199-215.

Fine, M. (2012). Troubling calls for evidence: A critical race, class and gender analysis of whose evidence counts. Feminism \& Psychology, 22, 3-19.

Fouad, N. A., Gerstein, L. H., \& Toporek, R. L. (2006). Social justice and counseling psychology in context. In R.L Toporek, L. Gerstein, N. Fouad, G. Roysircar, \& T. Israel (Eds.). Handbook for social justice in counseling psychology: Leadership, vision, and action (pp. 1-16). Thousand Oaks, CA: Sage Publications.

Grande, T., Dilg, R., Jakobsen, T., Keller, W., Krawietz, B., Langer, M., Oberbracht, C. , Stehle, S., Stennes, S., \& Rudolf, G. (2006). Differential effects of two forms of psychoanalytic therapy: Results of the Heidelberg-Berlin study. Psychotherapy Research, 16, 470-485.

Green, M. \& Elliott, M. (2010). Religion, health, and psychological well-being. Journal of Religion and Health, 49, 149-163.

Harper, D. J. (2013). On the persistence of psychiatric diagnosis: Moving beyond a zombie classification system. Feminism \& Psychology, 23, 78-85.

Heatherington, L., Messer, S. B., Angus, L., Strauman, T. J., Friedlander, M. L., \& Kolden, G. G. (2013). The narrowing of theoretical orientations in clinical psychology doctoral training. Clinical Psychology Science and Practice. 19, 364-374.

Heesoon, J. (2009). Social justice, multicultural counseling, and practice: Beyond a conventional approach. London: Sage Publications.

Henry, W. P. (1998). Science, politics, and the politics of science: The use and misuse of empirically validated treatment research. Psychotherapy Research, 8, 126-140. doi:10.1093/ptr/8.2.126

Hoffnung, M. (2005). No more blaming the victim: Therapy in the interest of social justice. Psychology of Women Quarterly, 29, 454-455. 
Hwang, W. (2009). The formative method for adapting psychotherapy (FMAP): A communitybased developmental approach to culturally adapting therapy. Professional Psychology: Research and Practice, 40, 369-377.

Jurist, E. L. (2013). Commentary on Norcross and Karpiak's 'Clinical psychologists in the 2010s: 50 years of the APA division of clinical psychology'. Clinical Psychology: Science and Practice, 20, 221-223.

Kirmayer, L. J. (2012). Cultural competence and evidence-based practice in mental health: Epistemic communities and the politics of pluralism. Social Science \& Medicine, 75, 249256.

Larsson, B. P. M., Broberg, A. G., \& Kaldo, V. (2013). Do psychotherapists with different theoretical orientations stereotype or prejudge each other? Journal of Contemporary Psychotherapy, 43, 169-178.

Levy, K. N. \& Anderson, T. (2013). Is clinical psychology doctoral training becoming less intellectually diverse? And if so, what can be done? Clinical Psychology: Science and Practice 20, 211-220.

Lorde, A. (1981). The uses of anger. Women's Studies Quarterly, 25, 278 - 285.

McComas, W. F. (2010) Ten myths of science: reexamining what we think we know about the nature of science. School, Science, and Mathematics, 96, 10-16.

McKleroy, V. S., Galbraith, J. S., Cummings, B., Jones, P., Harshbarger, C., Collins, C., ... \& ADAPT Team. (2006). Adapting evidence-based behavioral interventions for new settings and target populations. AIDS Education \& Prevention, 18, 59-73.

Miller, A. (2008). A critique of positive psychology—or 'The new science of happiness'. Journal of Philosophy of Education, 42, 591- 560.

Minieri, A. M., Reese, R. J., Miserocchi, K. M., \& Pascale-Hague, D. (2015). Using client feedback in training of future counseling psychologists: An evidence-based and social justice practice. Counselling Psychology Quarterly, 28, 305-323.

Moir-Bussy, A. (2012). Engaging counseling students in the dialogue between globalization and indigenization. Asia Pacific Journal of Counselling and Psychotherapy, 3, 41-49.

National Institute of Mental Health (NIMH). (2016). Psychotherapies. Retrieved from https://www.nimh.nih.gov/health/topics/psychotherapies/index.shtml\#part_153563 
Nebelkopf, E., King, J., Wright, S., Schweigman, K., Lucero, E., Habte-Michael, T., \& Cervantes, T. I. (2011). Growing roots: Native American evidence-based practices. Journal of Psychoactive Drugs, 43, 263-268.

Norcross, J. C., \& Karpiak, C. P. (2012). Clinical psychologists in the 2010s: 50 years of the APA division of clinical psychology. Clinical Psychology: Science and Practice, 19, 1-12.

Norcross, J. C., \& Lambert, M. J. (2011). Evidence-based therapy relationships. In J. C. Norcross (Ed.), Psychotherapy relationships that work: Evidence-based responsiveness (pp. 3 - 21). New York: Oxford University Press.

Orlinsky, D. E., Rønnestad, M. H., \& Willutzki, U. (2004). Fifty years of psychotherapy processoutcome research: Continuity and change. In M. Lambert (Ed.), Bergin and Garfield's Handbook of Psychotherapy and Behavior Change, 5th ed. (pp.307-389). New York: Wiley.

Paniagua, F. A. (2013). Culture-bound syndromes, cultural variations, and psychopathology. In F. A. Paniagua, A. Yamada, F. A. Paniagua, A. Yamada (Eds.), Handbook of multicultural mental health: Assessment and treatment of diverse populations (pp. 25-47). San Diego, CA: Elsevier Academic Press.

Parvisi, J. (2009). The Corticocentric myopia: Old bias in new cognitive sciences. Trends in Cognitive Sciences, 13, 354-359.

Pearce, S. (2014). DSM-5 and the rise of the diagnostic checklist. Journal of Medical Ethics: Journal of The Institute of Medical Ethics, 40, 515-516.

Pedersen, P.B. (2003). Culturally biased assumptions in counseling psychology. The Counseling Psychologist, 31, 396-403.

Pope, K. (2008). Why I resigned from the American Psychological Association. Retrieved from https://kspope.com/apa/

Prilleltensky, I. (1989). Psychology and the status quo. American Psychologist, 44, 795-802.

Rizvi, S. L. (2013). When insurance companies and clinicians pay attention to data, everybody wins: A commentary on Koons, O'Rourke, Carter, and Erhardt (2013). Cognitive and Behavioral Practice, 20, 325-327.

Rogers-Sirin, L., Melendez, F., Refano, C., \& Zegarra, Y. (2015). Immigrant perceptions of therapists' cultural competence: A qualitative investigation. Professional Psychology: Research and Practice, 46, 258-269. 
Salzman, M. B. (2006). "Culture Wars" and intercultural conflict from three theoretical perspectives. Paper presented at the XVIII International Congress of International Association of Cross Cultural Psychology (IACCP), Isle of Spetses, Greece

Salzman, M. B. (2008). Globalization, religious fundamentalism and the need for meaning. International Journal of Intercultural Relations, 32, 318 - 387.

Samuels, A. (2008). Forward. In R. House, \& D. Lowenthal, D. (Eds.). Against and for CBT: Towards a constructive dialogue? (pp. iii - v). Ross-on-Wye, UK: PCCS. Chicago.

Shechtman, Z. \& Pastor, R. (2005). Cognitive-behavioral and humanistic group treatment for children with learning disabilities: A comparison of outcomes and process. Journal of Counseling Psychology, 52, 322-336.

Stocker, M. (1996). Valuing emotions. Cambridge, UK: Cambridge University Press.

Stoudt, B. G., Fox, M., \& Fine, M. (2012). Contesting privilege with critical participatory action research. Journal of Social Issues, 68, 178-193.

Sue, D. W. (2016). Race talk and the conspiracy of silence: Understanding and facilitating difficult dialogues on race. Newark, NJ: John Wiley \& Sons.

Sue, D. W. \& Sue, D. (2012). Counseling the culturally diverse: Theory and practice. Hoboken, NJ: John Wiley and Sons.

Swartz, S. (2013). Feminism and psychiatric diagnosis: Reflections of a feminist practitioner. Feminism \& Psychology, 23, 41-48.

Wakefeld, J. C. (2013). Is complicated/prolonged grief a disorder? Why the proposal to add a category of complicated grief disorder to the DSM- 5 is conceptually and empirically unsound. In M. Stroebe, H. Schut, \& van den Bout, J. (Eds.). Complicated grief: Scientific foundations for healthcare professionals (pp. 99-114). New York, NY: Routledge/Taylor \& Francis Group.

Wampold, B. E., \& Imel, Z. E. (2015). The great psychotherapy debate: The evidence for what makes psychotherapy work, $2^{\text {nd }}$ ed. New York: Routledge/Taylor \& Francis Group.

Wendt, D. C., Gone, J. P., \& Nagata, D. K. (2015). Potentially harmful therapy and multicultural counseling: Bridging two disciplinary discourses. The Counseling Psychologist, 43, 334358. 
Journal for Social Action in Counseling and Psychology

Volume 9, Number 1, Summer 2017

Woolfolk, R. L., \& Richardson, F. C. (2008). Behaviour therapy and the ideology of modernity. In R. House, \& D. Loewenthal, D. (Eds.). Against and for CBT: Towards a constructive dialogue? (pp. 52 - 71). Ross-on-Wye, UK: PCCS. Chicago. 